\title{
Ezetimibe and simvastatin for the prevention of cardiovascular events in predialysis chronic kidney disease patients: a review
}

This article was published in the following Dove Press journal: International Journal of Nephrology and Renovascular Disease 19 December 2012

Number of times this article has been viewed

\author{
Sahar Naderi ${ }^{1}$ \\ JoAnne M Foody² \\ 'Heart and Vascular Institute, \\ Cleveland Clinic Foundation, \\ Cleveland, $\mathrm{OH}, \mathrm{USA} ;{ }^{2}$ Division of \\ Cardiovascular Medicine, Brigham and \\ Women's Hospital, Boston, MA, USA
}

Correspondence: JoAnne Foody Cardiovascular Wellness Program, Brigham and Women's Hospital, 75 Francis Street, Boston, MA 02II5, USA $\mathrm{Tel}+\mathrm{I} 8573071989$

Fax + I 8573071955

Email jfoody@partners.org

\begin{abstract}
The majority of chronic kidney disease patients die of cardiovascular disease prior to reaching end-stage renal disease. The combination of ezetimibe and a statin has been the focus of a number of recent studies, given initial data showing a substantial reduction in low-density lipoprotein with the addition of ezetimibe. However, it is unclear how this low-density lipoprotein reduction impacts cardiovascular disease outcomes. This review will briefly discuss the burden of cardiovascular disease and the pathophysiology of dyslipidemia in chronic kidney disease patients. It will then assess the data regarding the impact of adding ezetimibe to a statin on the general population, and specifically predialysis chronic kidney disease patients.
\end{abstract}

Keywords: ezetimibe, simvastatin, chronic kidney disease, cardiovascular, prevention

\section{The burden of cardiovascular disease in the CKD patient}

The prevalence of chronic kidney disease (CKD) is steadily increasing in the United States, with approximately 8 million individuals afflicted with the disease and 300,000 of them requiring renal replacement therapy. ${ }^{1}$ While studies show that CKD eventually progresses to the point of needing renal replacement therapy, the majority of patients die of cardiovascular disease prior to reaching end-stage renal disease (ESRD). ${ }^{2}$ In fact, cardiovascular disease is the primary cause of mortality in these patients. ${ }^{3}$ Therefore, research is now being focused on cardiovascular prevention strategies specific to this patient population.

Management of hyperlipidemia (HL) has long been recognized as one of the cornerstones of primary and secondary prevention in coronary artery disease. Low-density lipoprotein (LDL) reduction is known to decrease mortality in the general population. ${ }^{4,5}$ However, the impact of treating HL in CKD has been less clear. Given the wealth of data on the mortality benefit of 3-hydroxy-3-methylglutaryl-coenzyme A inhibitors (ie, statins) in the general population, this group of drugs has garnered the most attention. Subgroup analyses of several statin studies have suggested that patients with predialysis CKD do see a mortality benefit from initiation of a statin. ${ }^{6,7}$ In contrast, two large prospective randomized trials, Die Deutsche Diabetes Dialyse Studie (4D) ${ }^{8}$ and A Study to Evaluate the Use of Rosuvastatin in Subjects on Regular Hemodialysis (AURORA) found no benefit of statins in ESRD patients. These data suggest that treatment of HL may be more beneficial in predialysis CKD patients than in those with ESRD. It has been suggested that the mechanism of cardiovascular mortality in ESRD patients may be different from that of predialysis CKD patients or the general population. Others have 
posited that atherosclerosis may be too far advanced once patients reach ESRD. ${ }^{10,11}$

\section{Pathophysiology of dyslipidemia in chronic kidney disease}

Studies suggest that the pathophysiology of dyslipidemia in those with CKD may be different than that of the general population. Changes in a number of key enzymes and receptors in CKD result predominantly in dysregulation of highdensity lipoprotein (HDL) and triglyceride metabolism. ${ }^{12}$ Reduction in apoprotein (Apo)A-I and ApoA-II leads to low HDL cholesterol levels. Chronic inflammation also contributes to low HDL cholesterol levels by reducing plasma albumin, which serves as a carrier of cholesterol from peripheral tissues to HDL. ${ }^{13} \mathrm{An}$ increase in ApoC-III levels in CKD results in elevation in triglycerides by inhibiting lipoprotein lipase, an enzyme that breaks down triglyceriderich particles. ${ }^{13}$ While a reduction in HDL cholesterol and an elevation in triglycerides are common lipid disturbances in CKD, LDL cholesterol is often normal in these patients in the absence of nephrotic syndrome. . $^{14,15}$

Those with ESRD are known to have particularly low plasma cholesterol levels. There is some thought that this signifies intense inflammation, which could be one of the primary drivers of increased cardiovascular disease risk in this group. Although LDL levels are lower in these patients, they "tend to be smaller, denser, and therefore more atherogenic," ${ }^{15,16}$ so it remains that LDL cholesterol may still play a vital role in cardiovascular disease in these patients. ${ }^{16}$ Given the potentially unique pathophysiology of cardiovascular disease in ESRD patients, conventional lipid management for primary and secondary prevention may not prove to be as beneficial in this group as the general population. This may partially explain the results seen in the 4D and AURORA trials discussed earlier. The pathophysiology of dyslipidemia and cardiovascular disease in earlier stages of CKD is less clear, but is thought to be more closely related to that of the general population. Therefore, this review will predominantly focus on the impact of HL management, specifically with ezetimibe and simvastatin, on predialysis CKD.

\section{Ezetimibe and simvastatin in the general population}

Ezetimibe is a Niemann-Pick C1-like 2 protein blocker that potently inhibits the absorption of cholesterol from the gastrointestinal and biliary systems. ${ }^{17}$ Because of the drug's good safety profile ${ }^{18}$ as well as its reported significant reduction in markers thought to impact cardiovascular outcomes, such as LDL and C-reactive protein (CRP), ${ }^{19}$ it was initially hailed as an important first-line addition to HL management. The addition of ezetimibe to a statin has since become the focus of a number of recent studies. Pearson et a ${ }^{19}$ identified patients with primary HL and compared the degree of LDL reduction for those treated with ezetimibe and simvastatin versus simvastatin versus atorvastatin versus placebo. They found a significant reduction in LDL with simvastatin and ezetimibe versus simvastatin or atorvastatin alone, regardless of the dose of statin. In the pooled analysis, there was a 52.5\% reduction in LDL in the ezetimibe-simvastatin group versus $38 \%$ in the simvastatin group $(P=<0.001)$. Similar findings were noted in the ezetimibe-atorvastatin versus atorvastatin groups (53.4\% vs $45.3 \%$, respectively; $P<0.001$ ). They also noted significant decreases in CRP. Although the study showed a significant decrease in LDL and CRP levels, it did not evaluate the impact of the addition of ezetimibe on major cardiovascular end points.

Another study, the Simvastatin and Ezetimibe in Aortic Stenosis (SEAS) trial, ${ }^{20}$ enrolled 1873 patients with mild to moderate aortic stenosis and randomized them to either $40 \mathrm{mg}$ of simvastatin and $10 \mathrm{mg}$ ezetimibe or placebo. They found a statistically significant decrease in ischemic cardiovascular events in the treatment arm, but noted that this was mainly due to a smaller number of patients undergoing coronary artery bypass grafting in this group. It did not answer the question of the impact of adding ezetimibe to a statin versus using a statin alone, given there was no simvastatin arm of the trial. Therefore, despite the reduction of LDL seen with the addition of ezetimibe, these studies have yet to show further cardiovascular mortality benefit of ezetimibe in addition to a statin versus a statin alone in the general population. ${ }^{20,21}$

The Ezetimibe and Simvastatin in Hypercholesterolemia Enhances Atherosclerosis Regression (ENHANCE) trial $^{21}$ sought to evaluate further the effect of ezetimibe on major adverse cardiovascular events. The study included 720 patients with familial hypercholesterolemia and stratified them to $80 \mathrm{mg}$ of simvastatin and $10 \mathrm{mg}$ of ezetimibe versus $80 \mathrm{mg}$ of simvastatin alone and measured the intimamedia thickness (IMT) over a 24-month period. Studies have shown IMT to be a valid surrogate marker for major adverse cardiovascular events, including stroke, angina, and myocardial infarction (MI). ${ }^{22,23}$ The researchers found no statistically significant difference in progression of IMT between the treatment arms, although they again demonstrated a statistically significant reduction in LDL, CRP, and triglyceride levels. The authors of ENHANCE suggest that 
the results may be due to a "ceiling effect," in which there is little added benefit beyond what is provided by a high-dose statin alone. They also provide several other mechanisms by which statins may slow progression of atherosclerosis outside of LDL reduction. Studies have shown a small albeit significant reduction in blood pressure with incremental increased reduction with increasing blood pressure. ${ }^{24}$ There is also an anti-inflammatory effect and an improvement in endothelial function that has been observed in scientific models. ${ }^{25}$ Data also suggest that statins may have beneficial effects on CKD not related to LDL reduction, which will be discussed in a later section.

The Improved Reduction of Outcomes: Vytorin Efficacy International Trial (IMPROVE-IT) ${ }^{26}$ should help answer the question of the utility of adding ezetimibe to a statin. Scheduled to be completed sometime in 2013, IMPROVE-IT has enrolled approximately 18,000 patients (including patients with CKD) stabilized after acute coronary syndrome and randomized them to receive either simvastatin $40 \mathrm{mg}$ or simvastatin $40 \mathrm{mg}$ plus ezetimibe $10 \mathrm{mg}$. The primary end points of treatment will be the first occurrence of cardiovascular death, nonfatal MI, rehospitalization for unstable angina, coronary revascularization within 30 days of presentation with acute coronary syndrome, or stroke. The goal of the study is ultimately to determine the cardiovascular mortality benefit of adding ezetimibe to current lipid therapy and also to evaluate the impact of further lowering of LDL. It should be noted that patients enrolled in the trial are already at their recommended LDL goal.

\section{Ezetimibe and simvastatin in chronic kidney disease}

Currently, the Study of Heart and Renal Protection (SHARP) trial ${ }^{27}$ is the only study looking specifically at the impact of aggressive LDL-lowering combination therapy with ezetimibe and simvastatin on cardiovascular clinical outcomes in CKD patients. The study was a randomized double-blinded trial that enrolled patients 40 years and older with CKD (including ESRD patients) and an average LDL of approximately $108 \mathrm{mg} / \mathrm{dL}$. They initially randomized 9438 patients to simvastatin $20 \mathrm{mg}$ plus ezetimibe $10 \mathrm{mg}$ versus simvastatin $20 \mathrm{mg}$ versus placebo. Patients were randomized in this manner for 1 year to determine the safety of ezetimibe plus simvastatin in these patients. After 1 year, the majority of the patients in the simvastatin group were rerandomized to simvastatin $20 \mathrm{mg}$ plus ezetimibe $10 \mathrm{mg}$ or placebo and followed for an average of 4 years. The goal LDL reduction was $1 \mathrm{mmol} / \mathrm{L}$ ( or $39 \mathrm{mg} / \mathrm{dL}$ ) based on previous data that showed this would result in a one-fifth reduction in cardiovascular events. ${ }^{28}$

Recent studies demonstrate that more aggressive LDL reduction with high-dose statins leads to improved cardiovascular outcomes in the general population. ${ }^{6,29-31}$ Although research demonstrates high-dose statins to be safe and effective in the general population, ${ }^{32}$ there is general concern among practitioners regarding the safety of higher doses in CKD patients. Guidelines for therapy indicate that statins with minimal renal excretion (ie, pravastatin, atorvastatin, simvastatin) do not need to be dose-adjusted in predialysis CKD patients. ${ }^{13}$ However, there have been no studies to date looking at high-dose statins specifically in CKD patients. As previously mentioned, the addition of ezetimibe to a statin also results in a significantly greater reduction in LDL. ${ }^{33}$ Therefore, in the SHARP study the decision was made to use the combination of ezetimibe and simvastatin to achieve aggressive LDL reduction, ${ }^{33}$ due to concerns for myopathy and other potential side effects with high-dose statin therapy.

The initial goal of the study was not necessarily to determine the efficacy of the combination of ezetimibe and simvastatin on outcomes in CKD, but to determine the impact of LDL reduction on outcomes as renal impairment progresses. The authors state that "when eGFR [estimated glomerular filtration rate] falls below $30 \mathrm{~mL} / \mathrm{min}$, a different cardiovascular pathology emerges, with vascular stiffness and calcification, structural heart disease, sympathetic overactivity contributing to an increasing risk of cardiac arrhythmia and heart failure. ${ }^{27,34}$ The potential differences in cardiovascular mortality between the general population and those with CKD were highlighted in the 4D trial, ${ }^{8}$ in which $21 \%$ of the cardiac deaths were due to MI in the general population versus 59\% from sudden cardiac death in the ESRD group. The authors suggested that dysrhythmias may be the major cause of cardiovascular mortality in those with CKD (at least in ESRD patients), and therefore aggressive lipid management may not improve outcomes in these patients.

The study found that ezetimibe plus simvastatin resulted in a statistically significant decrease in major atherosclerotic events versus placebo $(11.3 \%$ versus $13.4 \%$; relative risk [RR] 0.83, $P=0.0021)$. Major atherosclerotic events included coronary events (nonfatal MI and coronary death), nonhemorrhagic stroke, or revascularization procedure. When analyzed separately, there was no statistically significant difference in coronary events, although there was a difference in nonhemorrhagic stroke and revascularization procedures. The authors note that the study was not powered 
sufficiently to look at these atherosclerotic event categories separately. When the results were analyzed for those on dialysis and those not on dialysis, there was no heterogeneity between groups $\left(\chi^{2}=1.34, P=0.25\right)$, although there was a statistically significant difference in atherosclerotic events in the nondialysis patients $(\mathrm{RR}=0.78$, confidence interval 0.67-0.91), whereas the difference did not reach statistical difference in the dialysis patients $(\mathrm{RR}=0.90$, confidence interval 0.75-1.08). There was also a trend towards decreased atherosclerotic events in the intervention group when patients were stratified by GFR.

Based on these results, the authors concluded that simvastatin $20 \mathrm{mg}$ plus ezetimibe $10 \mathrm{mg}$ "safely reduced the incidence of major atherosclerotic events in a wide range of patients with advanced chronic kidney disease." The study also suggests that the benefit of treating hyperlipidemia is seen across various degrees of CKD, although the outcomes typically evaluated (ie, coronary events categorized as nonfatal MI and cardiovascular-related death) were part of a greater composite end point and did not show statistical significance alone.

Given the study was underpowered specifically for coronary events, we can conclude that there was a trend towards a significant decrease in these types of events when aggressively treating hyperlipidemia in CKD patients. It does not, however, give an indication of the benefits of the addition of ezetimibe to simvastatin, given ezetimibe and simvastatin were compared to placebo alone. If the trial had continued with the initial inclusion of simvastatin alone, the study may have given more insight into this question. There is also the question of whether statins work outside of LDL reduction in CKD patients. Some studies indicate a decrease in proteinuria in CKD patients treated with statins, thereby delaying the progression of disease, although the data on this have been mixed. ${ }^{35,36}$ Results from SHARP suggest that those with higher baseline urinary albumin:creatinine ratios $(>30 \mathrm{mg} / \mathrm{g})$ saw a greater benefit of simvastatin plus ezetimibe versus placebo alone. This suggests that statins may play a role in delaying progression of $\mathrm{CKD}$, although this requires further investigation.

\section{Future directions}

The SHARP trial suggests that there is a role for treating hyperlipidemia across all spectrums of CKD. However, there are still lingering questions as to whether the benefits of statins are due to other mechanisms beyond their lipidlowering effects, making the utility of adding ezetimibe uncertain. Regardless of the questionable benefit of adding ezetimibe to a statin, ezetimibe does play a role in current management. For those patients who cannot tolerate highdose statins and/or cannot reach their LDL goal, the addition of ezetimibe may prove beneficial, particularly given its safety profile in CKD.

There has been no study of the impact of ezetimibe plus a statin versus a statin alone on CKD patients, although the ongoing IMPROVE-IT ${ }^{26}$ is supposed to provide further insight into this question. Results of this trial will provide more guidance as to how this drug combination should be used in primary and secondary prevention of cardiovascular disease in the general population. The expected subgroup analysis of CKD patients will also provide insight into how this drug combination plays a role in cardiovascular disease prevention in CKD patients.

\section{Disclosure}

JoAnne Foody is a consultant for Merck. Sahar Naderi reports no conflicts of interest in this work.

\section{References}

1. Sarnak MJ, Levey AS, Schoolwerth AC, et al. Kidney disease as a risk factor for development of cardiovascular disease: a statement from the American Heart Association Councils on Kidney in Cardiovascular Disease, High Blood Pressure Research, Clinical Cardiology, and Epidemiology and Prevention. Hypertension. 2003;42(5):1050-1065.

2. Shulman NB, Ford CE, Hall WD, et al. Prognostic value of serum creatinine and effect of treatment of hypertension on renal function. Results from the hypertension detection and follow-up program. The Hypertension Detection and Follow-up Program Cooperative Group. Hypertension. 1989;13(Suppl 5):I80-I93.

3. Foley RN, Collins AJ. End-stage renal disease in the United States: an update from the United States Renal Data System. J Am Soc Nephrol. 2007;18(10):2644-2648.

4. Baigent C, Keech A, Kearney PM, et al. Efficacy and safety of cholesterol-lowering treatment: prospective meta-analysis of data from 90,056 participants in 14 randomised trials of statins. Lancet. 2005;366(9493):1267-1278.

5. Thavendiranathan P, Bagai A, Brookhart MA, Choudhry NK. Primary prevention of cardiovascular diseases with statin therapy: a meta-analysis of randomized controlled trials. Arch Intern Med. 2006;166(21):2307-2313.

6. Heart Protection Study Collaborative Group. MRC/BHF Heart Protection Study of cholesterol lowering with simvastatin in 20,536 high-risk individuals: a randomised placebo-controlled trial. Lancet. 2002;360(9326):7-22.

7. Tonelli M, Moye L, Sacks FM, Kiberd B, Curhan G. Pravastatin for secondary prevention of cardiovascular events in persons with mild chronic renal insufficiency. Ann Intern Med. 2003;138(2):98-104.

8. Wanner C, Krane V, März W, et al. Atorvastatin in patients with type 2 diabetes mellitus undergoing hemodialysis. NEngl J Med. 2005;353(3): 238-248.

9. Fellstrom BC, Jardine AG, Schmieder RE, et al. Rosuvastatin and cardiovascular events in patients undergoing hemodialysis. $N$ Engl J Med. 2009;360(14):1395-1407.

10. Herzog CA, Mangrum JM, Passman R. Sudden cardiac death and dialysis patients. Semin Dial. 2008;21(4):300-307.

11. Guérin AP, Pannier B, Marchais SJ, London GM. Arterial structure and function in end-stage renal disease. Curr Hypertens Rep. 2008;10(2): 107-111. 
12. Vaziri ND. Dyslipidemia of chronic renal failure: the nature, mechanisms, and potential consequences. Am J Physiol Renal Physiol. 2006;290(2):F262-F272.

13. Harper CR, Jacobson TA. Managing dyslipidemia in chronic kidney disease. J Am Coll Cardiol. 2008;51(25):2375-2384.

14. Kalaitzidis RG, Elisaf MS. The role of statins in chronic kidney disease. Am J Nephrol. 2011;34(3):195-202.

15. Chmielewski M, Carrero JJ, Nordfors L, Lindholm B, Stenvinkel P. Lipid disorders in chronic kidney disease: reverse epidemiology and therapeutic approach. J Nephrol. 2008;21(5):635-644.

16. O’Neal D, Lee P, Murphy B, Best J. Low-density lipoprotein particle size distribution in end-stage renal disease treated with hemodialysis or peritoneal dialysis. Am J Kidney Dis. 1996;27(1):84-91.

17. van Heek M, Farley C, Compton DS, Hoos LM, Smith-Torhan A, Davis HR. Ezetimibe potently inhibits cholesterol absorption but does not affect acute hepatic or intestinal cholesterol synthesis in rats. Br J Pharmacol. 2003;138(8):1459-1464.

18. Landray M, Baigent C, Leaper C, et al. The second United Kingdom Heart and Renal Protection (UK-HARP-II) Study: a randomized controlled study of the biochemical safety and efficacy of adding ezetimibe to simvastatin as initial therapy among patients with CKD. Am J Kidney Dis. 2006;47(3):385-395.

19. Pearson T, Ballantyne C, Sisk C, Shah A, Veltri E, Maccubbin D. Comparison of effects of ezetimibe/simvastatin versus simvastatin versus atorvastatin in reducing $\mathrm{C}$-reactive protein and low-density lipoprotein cholesterol levels. Am J Cardiol. 2007;99(12):1706-1713.

20. Rossebo AB, Pedersen TR, Boman K, et al. Intensive lipid lowering with simvastatin and ezetimibe in aortic stenosis. $N$ Engl J Med. 2008;359(13):1343-1356.

21. Kastelein JJ, Akdim F, Stroes ES, et al. Simvastatin with or without ezetimibe in familial hypercholesterolemia. $N$ Engl J Med. 2008; 358(14):1431-1443.

22. Bots ML, Hoes AW, Koudstaal PJ, Hofman A, Grobbee DE. Common carotid intima-media thickness and risk of stroke and myocardial infarction: the Rotterdam Study. Circulation. 1997;96(5):1432-1437.

23. Amarenco P, Labreuche J, Lavallee P, Touboul PJ. Statins in stroke prevention and carotid atherosclerosis: systematic review and up-to-date meta-analysis. Stroke. 2004;35(12):2902-2909.

24. Strazzullo P, Kerry SM, Barbato A, Versiero M, D'Elia L, Cappuccio FP. Do statins reduce blood pressure? A meta-analysis of randomized, controlled trials. Hypertension. 2007;49(4):792-798.
25. Schönbeck U, Libby P. Inflammation, immunity, and HMG-CoA reductase inhibitors: statins as antiinflammatory agents? Circulation. 2004;109(21 Suppl 1):II18-II26.

26. Cannon CP, Giugliano RP, Blazing MA, et al. Rationale and design of IMPROVE-IT (IMProved Reduction of Outcomes: Vytorin Efficacy International Trial): comparison of ezetimbe/simvastatin versus simvastatin monotherapy on cardiovascular outcomes in patients with acute coronary syndromes. Am Heart J. 2008;156(5):826-832.

27. Baigent C, Landray MJ, Reith C, et al. The effects of lowering LDL cholesterol with simvastatin plus ezetimibe in patients with chronic kidney disease (Study of Heart and Renal Protection): a randomised placebo-controlled trial. Lancet. 2011;377(9784):2181-2192.

28. Baigent C, Blackwell L, Emberson J, et al. Efficacy and safety of more intensive lowering of LDL cholesterol: a meta-analysis of data from 170,000 participants in 26 randomised trials. Lancet. 2010;376(9753):1670-1681.

29. Cannon CP, Steinberg BA, Murphy SA, Mega JL, Braunwald E. Meta-analysis of cardiovascular outcomes trials comparing intensive versus moderate statin therapy. J Am Coll Cardiol. 2006;48(3): $438-445$.

30. LaRosa JC, Grundy SM, Waters DD, et al. Intensive lipid lowering with atorvastatin in patients with stable coronary disease. $N$ Engl J Med. 2005;352(14):1425-1435.

31. Pedersen TR, Faergeman O, Kastelein JJ, et al. High-dose atorvastatin vs usual-dose simvastatin for secondary prevention after myocardial infarction: the IDEAL study: a randomized controlled trial. JAMA. 2005;294(19):2437-2445.

32. Armitage J. The safety of statins in clinical practice. Lancet. 2007;370(9601):1781-1790

33. Davidson MH, McGarry T, Bettis R, et al. Ezetimibe coadministered with simvastatin in patients with primary hypercholesterolemia. $J \mathrm{Am}$ Coll Cardiol. 2002;40(12):2125-2134.

34. Foley RN, Parfrey PS, Sarnak MJ. Clinical epidemiology of cardiovascular disease in chronic renal disease. Am J Kidney Dis. 1998; 32(5 Suppl 3):S112-S119.

35. Agarwal R. Effects of statins on renal function. Am J Cardiol. 2006; 97(5):748-755.

36. Abbate M, Zoja C, Corna D, Capitanio M, Bertani T, Remuzzi G. In progressive nephropathies, overload of tubular cells with filtered proteins translates glomerular permeability dysfunction into cellular signals of interstitial inflammation. J Am Soc Nephrol. 1998;9(7):1213-1224.

\section{Publish your work in this journal}

The International Journal of Nephrology and Renovascular Disease is an international, peer-reviewed open-access journal focusing on the pathophysiology of the kidney and vascular supply. Epidemiology, screening, diagnosis, and treatment interventions are covered as well as basic science, biochemical and immunological studies. The journal welcomes

\section{Dovepress}

original research, clinical studies, reviews \& evaluations, expert opinion and commentary, case reports and extended reports. The manuscript management system is completely online and includes a very quick and fair peerreview system, which is all easy to use. Visit http://www.dovepress.com/ testimonials.php to read real quotes from published authors. 